\title{
Reading Profiles in Indonesian Context: Concurrent Protocol Analysis
}

\author{
Abidin Pammu \\ English Department, Faculty of Cultural Studies Hasanuddin Univeristy, Makassar, Indonesia \\ Email address: \\ abidinpammu60@yahoo.com \\ To cite this article: \\ Abidin Pammu. Reading Profiles in Indonesian Context: Concurrent Protocol Analysis. International Journal of Language and Linguistics. \\ Vol. 5, No. 5, 2017, pp. 143-150. doi: 10.11648/j.ij11.20170505.14
}

Received: October 25, 2016; Accepted: August 9, 2017; Published: September 7, 2017

\begin{abstract}
Verbal protocols have been used to construct proposition about cognitive process in language learning and reading process. Despite extensive development of cognitive -based research in reading strategies, revelations of cognitive process as well as its relation to proficiency are still inconclusive and more studies are still needed to venture into this field. There is a need to add existing literature in order to refresh current inconsistency regarding the relationship between proficiency and reading strategy. The paper reports the findings of a case study research at one of public university in Makassar, Indonesia. Five less proficient learners at English Department, Hasanuddin University participated in a six-weeks training. The verbal reports were recorded, transcribed, and then analyzed qualitatively by means of interpretative paradigm. Findings showed that less proficient EFL learners performed wide range of strategies, such as skimming, as well as compensation strategy of codeswitching, and sounding out words to help their comprehension process. These learners tended to employ those strategies in less efficient manner so as to read the text line by line. Variability in the use of strategies did not fully support these learners' comprehension over the text as indicated in the way they approached the tasks as well as their performance results in task completion. Lexical problem was indicative to account for their comprehension problem as shown in their report for willing to use ssupport strategy, such as the use of dictionary. Overall, the less proficient learners performed almost all of the important reading strategies commonly practiced by the proficient learners of ESL background. The findings strengthen previous proposition that no consensus can be drawn between certain pattern of strategy use in relation to proficiency level. The finding confirmsan emerging need of reading strategy instruction in order to generate strategic reading behaviour in these learners.
\end{abstract}

Keywords: Verbal Reports, Less Proficient Learners, Cognitive Reading Strategies, Cognitive Process, Strategy Instruction

\section{Introduction}

At present, the Indonesian government demands its people to acquire high standard of English in reading as a result of global necessity in knowledge transfer of science and technology. More recently, the government of Indonesia through the Department of Education and Culture has urged its people all over the country to improve their literacy skills in order to be able to challenge the dynamic development of globalization era (Abidin, et al. 2012). The needs for this reading proficiency in academic setting at university level has already gathered momentum for the last few decades and has been a challenge for teaching professionals and educators in the country. Whitehead (2007) confirms that this mission is relevant to the need of language proficiency as an essential condition for its people in order to gain resistant survival in this fast changing society. Reading necessity does not only prevail within EFL setting, such Indonesia but also in ESL context. Koo Yew Lie and Peter Kell (2006) advocate that in recent times there has been rising educational concern about transitions between academic literacies and work place literacies in Malaysia.

Vitality of the language skill and its importance in the world of global economy is apparent in a scholar's statement. Richards (2008) states that one of the simple facts of life in the present time is that English language skills of a good proportion of its citizenry are seen as vital if a country is to participate actively in the global economy and to have access to the information and knowledge that provide the basis for both social and economic development. He further convinces that central to this enterprise are English teaching and English language teacher education. However, the learning 
and teaching of English in Indonesian tertiary education has faced some challenges. More and more tertiary learners find it difficult to read and understand academic text in their respective subject disciplines. Recent investigation of the reading behaviour of EFL learners in Indonesia demonstrated that their main motivation to read was for fulfilling the assignment (Erna Iftanti, 2012). Propositions and believes about the unsatisfactory performance of EFL learners from teaching practitioners brought important issues both present and future development of reading research.

The apparent under performance of tertiary learners has raised questions about current development of teaching and learning a foreign language in Indonesia. The development of language teaching does not seem to provide significant impact on the improvement of learners' poor standard of EFL performance particularly in reading skills. An attempt to develop the English curriculum does not come into effect due to successive change in educational policy enforced by the ministry of education as an impact of cabinet reshuffling every time during presidential succession. It is essential, therefore, that teaching practitioners in foreign language education in Indonesia take account for the research-based reading as the basis for improving learners' poor reading performance. Teaching practitioners as well as educators in the country are constantly seeking better ways of improving the teaching expertise with the provision of teacher training at both school and tertiary levels.

Recent account of the reading process highlights the importance of cognitive strategies in order to gain comprehension of the difficult text. Understanding learners' reading strategies also accounts for the improvement of proficiency in reading. Shorey and Mohktari (2001), for example, confirm that in order to improve reading proficiency and to design reading development programme we need to understand the learners' reading strategies. Understanding cognitive strategy is important because it deals with mental process which is directly concerned with the processing of information in order to learn, obtain, store, and retrieve information (Willian \& Burden, 1997). Gardner and McIntyre (1991) confirm that when second language learners are highly motivated to accomplish a learning task, they will use more strategies, cognitive and metacognitive, be more determined in maintaining effort and are attentive to the task at hand. On the other hand, if learners are unmotivated, then, they will exhibit negative behavior, feelings, and cognitions that affect their learning process. On this basis, investigating the reading knowledge and strategic processes of EFL context could help improve reading instruction and to inform the construction of the alternative model of effective reading. This paper highlights the less proficient EFL learners reading strategy profiles based on a case study employing verbal report analysis.

\section{Prevailing Issues About Learner and Strategy}

Current review of many years of research in learning and reading strategy comes up with a wider perspectives about learner and strategy. Walter (2007), for example, reviews that there is a link between successful learning and learners' strategy use both outside and inside classroom. Learners who employ particular strategies or have access to wider range of strategies learn more successfully than those who do not. She further states that "the ways in which strategies are used not simply for learning but are bound up in identity work for learners and have implications for how learners are seen and assessed (Walter, 2007:54). In addition, Grenfell (2007) elaborates the issue who confirms that strategy that good learners use presents underlying process which are linked to proficiency and specific task. The strategy enhances autonomy which is also linked to good language learning where the adoption conform to individual differences and learning styles. Oxford and Nykos (1989) are skeptical about the domain of strategy and motivation when they assert that it is not clear whether strategy use aids motivation or just the other way round. In support of this notion, Graham (2007) also concludes that the impetus of many years of language learners strategies has been to uncover what distinguishes effective learners from less effective one. While this current review is still inclusive about the issue of strategy and efficient or successful learner, it may be helpful to take account Mercer \& Ryan (2011) who conclude that in the domain of foreign language learning, certain learners are simply fifted or good language learner.

\section{The Nature of Reading Process}

Accrording to the National Accessible Reading Assessment Projects (2006:5), "reading is an active and complex process that involves understanding written text; developing and interpreting meaning; and using meaning as appropriate to type of text, purpose, and situation." This conception contains assurance of foundational skills to comprehend a variety of texts, including an expository text. When the text is brought into the reader's mind, the words begin to form meanings based on the reader's prior knowledge, experience, feelings, memories, and associations called forth by the act of reading (Alvermann \& Phelps, 2002). In any academic or higher learning context, reading is a crucial skill as it requires learners to process information from texts. Through this interaction, readers are required to synthesize, evaluate, and interpret the text so as to create meaning and develop knowledge from the text (Noorizah Mohd. Noor, 2010).

As part of receptive skill, reading has been widely perceived as a process of cognition that works within the mind. As a cognitive process, reading involves processes that constitute a beginning state, an intervening transformation, and an end state (Bernhardt, 1991). Taking into account Just and Carpenter's (1987) view, a reading process involves what information in the text that accounts for as a point of departure, how long the process takes, what information used during the process, and what the reader has learned when the process is finished. They maintain that understanding 
cognitive process means understanding the interpersonal problem-solving process that takes place within a learner' brain knowledge structures.

Reading comprehension is generally viewed in cognitive theory as consisting of active and complex processes in which individual construct meaning from written information (Call, 1985). The mental processes necessary for comprehending aural and written text are sufficiently similar of comprehension of both can generally be discussed as a common phenomenon. Anderson (1985) distinguishes comprehension into three interrelated processes that include perceptual processing, parsing, and utilization. In perceptual processing, learner's attention focusses on oral or written text with portion of the text being retained in short term memory. The capacity limitation of short term memory prevents specific word sequences from being retained longer than a few seconds. This happens due to incoming information that tends to replace the old information that had been retained in short term memory. Anderson (1985) maintains that while the text is still in short term memory some initial analysis of the language code may begin and encoding process gradually convert the text to meaningful representations.

In the context of ESL/EFL reading, Silberstein (1987) advocated three models of reading widely known as the bottom-up model, the top-down model, and the interactive model According to the bottom-up model, reading is a process of manipulating phoneme-grapheme relationships. Cahyono and Widiarti (2006) conclude that in the ESL/EFL teaching context, the application of this theory is evident in the adoption of instructional strategies stressing the active role of learners as readers. These include guessing the meaning of words from the context, previewing an article before reading it in order to have an overall view of this article, and actively predicting the sauthor's main points. They maintain that in such a process, the reader uses his/her knowledge of vocabularies, sentences, discourses, and knowledge of the world.

\section{Reading as Cognitive Process}

A cognitive strategy is a guide that serves the learners to develop internal procedure to enable them to perform hiher level of operation (Rosenshine et al. 1996). Skilled reading, therefore, is the ability to derive meaning from text accurately and efficiently. It requires both the ability to acquire the linguistic aspects and the ability to construct meaning from it (Mc-Cardle et al., 2001). All cognitive strategies share a common goal that is to teach students how to interact with the content so that learning become deliberate, self-directed, and self regulated (Jitendra et al. (2011).

Cognitive strategies are mental processes directly concerned with the processing of information in order to select, store, and retrieve incoming information (William \& Burden, 1997). Cognitive strategies engage with specific learning tasks that concern more direct manipulation of the learning materials (Brown et al, 1996). Therefore, becoming a skilled reader requires constant familiarity with linguistic aspect, such as phonology and alphabetic principle in order to comprehend the text (Mc Cardle \& Catts, 2001). Although sufficient instruction is essential for learners for word recognition, some learners struggle with comprehension of text despite adequate word recognition skill (Klingner \& Vaughn, 1996).

In general, studies in both L1 and L2 reading research provide a binary division of cognitive strategies as bottom up and top down (Ozek \& Civelek, 2007). When readers process the reading by decoding, identifying letter, word, phrases and then sentences in order to get the meaning then they approach the reading with bottom up process. On the contrary, when readers advocate the selection of the fewest and most productive elements from a text to make sense of it then it is a top-down process (Linch \& Hudson, 1991). The top -down model derived from a schematic theory of reading placing emphasis on the importance of reader's background knowledge in the reading process (Carrell, 1998). The complexities and dynamics of reader-text transaction have become important issues in the teaching of reading comprehension (Muhammad Kamarul Kabilan et al. (2010). Overall, cognitive reading strategy is a process which is defined as any overt purposeful effort or activity used by the reader to make sense of the printed material (Pearson, et al. 1992).

\section{Significance of the Study}

The present study will develop the existing literature of cognitive reading strategy for EFL context in Indonesia. The research data gathered will provide a foundation for other studies that are interested in investigating ESL/EFL reading. At a more practical level, the research findings will inform the practitioners of how less proficient EFL learners utilize their mental process to read an expository text in a specific context of EFL background.

From the theoretical perspectives, this study will provide additional perspective regarding cognitive strategy of the less proficient EFL learners, thus providing additional segment to current literature that mostly zooms at ESL backgrounds. From the pedagogical perspectives, this investigation will equip teaching practitioners with insights of less proficient learners reading profiles so that they can develop instructional materials suitable with particular level of proficiency. Awareness of learners' strategies is important in order to encourage better strategies for the sake of selfempowerment. Integrating this issue to the existing demands is useful for improving EFL reading skills which will in turn improve learners' futrure reading performance.

\section{Method of Data Collection and Analysis}

This study employs a purposeful sampling method to select the subjects. Five (5) less proficient learners were selected based on their latest gained TOEFL band score below 450 
which was used to qualify their proficiency level. Verbal protocol analysis was used to obtain the learners' profiles of cognitive reading strategy. Ericson and Simon (1984) assured that if successfully executed it provides a means for viewing invisible cognitive process. Data were obtained by tape recording the subject while performing a think-aloud by completing 6 (six) true-false statements on an expository text. This method of obtaining protocols was more reliable than other method, such as retrospection because the former provided a large number of possible reports with heeded information (Ericson and Simon, 1984). The protocols were transcribed and analyzed by means of a qualitative paradigm. To obtain trustworthy assessment about text suitability, content experts were involved to rate its level of difficulty. Careful considerations regarding the running of think-aloud protocol has been given due care by taking Cohen (1998) recommendations into account. The researcher looked for commonalities in the process of constructing the framework of the so-called strategies emerged from the protocols.

\section{Findings and Discussion}

Findings

The modes of the verbal reports vary considerably among the subjects and emergence of grammatical errors provides the real outlook of learners' proficiency of English as a foreign language in a particular context in Indonesia. Using the framework of what constitutes as strategies by Cohen (1998), the following are less proficient learners' reading profiles that fall on two broad categories based on Oxford's (1990) learning strategy classification. The five less proficient learners performed wide range of strategy use that could be classified into two broad categories, direct and indirect strategy. The first category includes scanning, skimming, using the key word, analyzing context, reading the details, and inferring meaning from the context. Other performed strategy was compensation strategy that includes guessing and switching to L1. The second category includes identifying the task prior to reading, monitoring comprehension, and previewing the paragraph. These two broad reading strategies appeared to be used interchangeably by the less proficient learners during the think-aloud session. Oxford (1990) maintains that the use of such strategies will encourage greater self-direction which is important to become independent learner. Samples of verbal reports were randomly taken out from the whole group as presented in the following table.

Table 1. Summary of Findings of LPL Cognitive Reading Strategy Profiles.

\begin{tabular}{|c|c|c|}
\hline Verbal Reports & Reading Strategy & Types of Strategy \\
\hline $\begin{array}{l}\text { 1. 'the title is 'mosquito with a mkission'. and umm before err answer the question I } \\
\text { want to know about what err. what err the important word in the text. }\end{array}$ & 1. Using a key word & Cognitive strategy \\
\hline $\begin{array}{l}\text { 2. ' 'hmm//...//.... I did not get it....but I think it's err talks about cure. I think it that } \\
\text { meaning in Bahasa Indonesia 'dapat disembuhkan'. }\end{array}$ & 2. Code-switching & Compensation strategy \\
\hline $\begin{array}{l}\text { 3.' 'I think in line five until nine it talks about err how malaria is increasing each } \\
\text { year'. 'I think the answer is true'. }\end{array}$ & 3. Guessing/prediction & Compensation strategy \\
\hline 4.' Err...I don't know about curable, so that I need a dictionary to know that'. & 4. Using dictionary & Support strategy \\
\hline $\begin{array}{l}\text { 5.' so, I will err reread the paragraph four before I answer the question'. But err...oh I } \\
\text { think this has not relation with the statement five so I have to reread it again'. }\end{array}$ & 5. Rereading for details & Cognitive strategy \\
\hline 6. 'whether I don't know I can find find it paragraph one' & 6. Monitoring comp. & Metacognitive strategy \\
\hline 7.'okay...'mosquito with a mission' is the title' & 7. Previewing & Metacognitive strategy \\
\hline $\begin{array}{l}\text { 8.' because this is the first statement perhaps the answer is in paragraph one'. oh I } \\
\text { need to scan the next paragraph I think'. }\end{array}$ & 8. Scanning & Cognitive strategy \\
\hline $\begin{array}{l}\text { 9.' 'because this is the first statement perhaps the answer is in paragraph one'. } \\
\text { Whether I don't know I can find it paragraph one'. }\end{array}$ & 9. Skimming & Cognitive strategy \\
\hline $\begin{array}{l}\text { 10.'I think err.. the... between the err sentence in paragraph } 4 \text { and statement 'in the } \\
1950 \text { malaria was curable' err have the relation }\end{array}$ & 10. Linking ideas & Cognitive strategy \\
\hline 11.'hmm.. . paragraphs tell about statistics of malaria' & 11. Inferring meaning & Cognitive strategy \\
\hline 12. so, I will read the first statement before I read the first paragraph'. & 12. Setting the reading purpose & Metacognitive strategy \\
\hline
\end{tabular}

\section{Discussion}

\section{Direct Strategy}

Scanning (LPL3, LPL5)

The scanning strategy was only apparent in the restricted number of the less proficient learners (LPL3, LPL5). PL3 demonstrated an inconsistent strategy use that he performed when coming to a confusing point as he previewed the paragraph while reading the same part. He glanced at the most critical point of the text in order to understand his reading. His use of scanning strategy did not help him a lot to escape away from difficulty in recalling the text. Hebegan his reading by false assumption. He assumed that the answer of the first question would appear in order in the paragraph that led him to have inaccurate prediction when he said, 'because this is the first statement perhaps the answer is in paragraph one'. This learner was aware of the important use of scanning strategy but failed to employ the strategy properly to a relevant task. He verbalized in a sufficient manner of expression and said, 'oh I need to scan the next paragraph I think'. 
PL5 did not make use of scanning strategy clearly probably due to his restricted proficiency that inhibited him to verbalize more expressions. The first stage of his reading reflected vocabulary insufficiency when he was uncertain of the meaning of the word 'mission' the word that tertiary learners should be familiar. Then he decided to read the tasks in order to determine his reading purpose by looking at the six true-false statements at the end of the passage. The scanning strategy was not sufficiently expressed when he said, 'I need to read the statement one by one'. This strategy would help the learner to determine whether he or she needs to go further for details in order to ensure efficient time. He only demonstrated relatively insufficient remarks from the reading passage of about 250 words with six true-false questions.

Skimming (LPL3)

Although skimming is a poplar cognitive reading strategy, it appeared to be less effectively employed and with relatively small number of LPL learners. LPL 3 demonstrated a skimming strategy only within line ' 45 ' of the passage reflecting that much of his reading process was not based on appropriate strategy at the initial stage of his reading. The first few paragraphs already actually required skimming strategy to resolve the relevant task. He said, 'because this is the first statement perhaps the answer is in paragraph one'. Whether I don't know I can find it paragraph one'. The skimming strategy, for example, would be applicable at the beginning stage of reading in order to understand what the text concerned. In other words, he seemed to perform an active process of selecting information needed for completion of the task but he still needed to perform extra skills to make effective use of such reading skills. This learner, just like other less proficient learners, who merely performed restricted strategies for learning.

Guessing (LPL1, LPL2, LPL3)

Guessing strategy appears to be relatively more popular than other strategy within the LPL group. LPL1 demonstrated few occasions of her use of guessing strategy in different parts of the passage. Her initial use of guessing strategy already occurred at the first paragraph when she declared, 'I think in line five until nine it talks about err how malaria is increasing each year'. When it was time to resolve the task, she also performed guessing strategy when she expressed, 'I think the answer is true'. Her frequent use of guessing strategy might have been due to her lack of selfefficacy about proficiency in English as a foreign language. LPL2 tended to be more assertive in her use of guessing strategy than LPL1. She employed redundant expressions to imply the same meaning for declaring her strategy use. She stated, 'so that I think err...researcher err have not...have not found err vaccine for malaria so I think the answer is false'. Her attempt to complete the task was characterized by doubt and uncertainty led her to employ more predictions. LPL3 demonstrated the same tendency with LPL2 who tended to be more directive and assertive. He stated, 'this is the phrase and may be it has similar meaning of increase'. Overall, the three learners had trouble in performing the task that resulted in the deliberate use of compensation strategy. One of the most prominent restrictions was concerned with lexical item.

Setting the purpose of reading (LPL2, LPL5)

Setting the purpose of reading also appeared in LPL group notably with two learners. LPL2 demonstrated her use of reading purpose at the very beginning of her reading. She said, 'so, I will read the first statement before I read the first paragraph'. Her attempt to complete the task of the first question was characterized by doubt and uncertainty resulting in the use of compensation strategy. This learner did not begin her reading by means of a more appropriate strategy so that she actually did not get the main idea before she committed guessing strategy. Her limitation of the use of strategy was apparent when she had to express different things with the same expressions. LPL5 simplified his use of this strategy by reading the question in order to help him set up his reading purpose when he stated, 'and then...I need to read the question to make me easier to understand'. This learner did reasonably proper attempt for the tasks that scored four correct answers out of six attempts. Overall, both learners demonstrated difficulties most probably due to lack of reading experience reading an expository text.

Inferring meaning from context (LPL4, LPL5)

Two LPL learners performed inferring meaning from context. This strategy involves a high order of thinking to perform. LPL4 demonstrated his use of this strategy that concerned statistics who expressed, 'hmm...paragraph tells about statistics of malaria'. He declares the title of the reading in order to confirm what sort of task he was dealing with. He then declared the direction of the task by looking at the six statements that follow the reading. The processes that the learner went through indicated a consistent non-linear process of reading in order to indicate the cognitive process. The process itself indicates if the learner perceived information and responded to this information according to the stage of comprehension. This learner is also aware of the difficulty he was having and declared something when encountering difficult words that seemed common to EFL learner. LPL5 demonstrated a more apparent use of this strategy in a more convincing way. He stated, 40 years later malaria was making comeback...making comeback...hmm so malaria was curable before...yeah malaria was curable before'. His use of this strategy implies that the learner actually demonstrated important skills in reading and indicated an intra personal problem-solving task that took place within the cognitive domain.

Linking ideas from different paragraphs (LPL2, LPL4)

Although inking ideas from different paragraphs includes a high level of reading strategy, it also emerged in the LPL learners. LPL2 employed the strategy by integration of a particular sentence and a key word. She stated, 'I think err the...between the err sentence in paragraph four and statement in the 1950's malaria was curable err have the relation'. Linking different ideas from separate paragraphs was apparent in her use of strategy but she only did this to catch the main idea. This learner was not aware of the paragraph 
structure that conveys one controlling idea, supporting sentences and a concluding sentence. LPL4 also did integration of prediction to perform linking strategy. He said, 'I find that the line tells about err symptom of malaria and maybe...there is a...there is err relation about the statement and the line err...'. His language proficiency was rather low in comparison with other less proficient learner in the group. Back channeling was apparent so frequently in his remarks. Despite their low proficiency, both LPL2 and LPL4 did better performance in the task completion most probably due to their effective use of this strategy. These learners' performance in reading has led the researcher to conclude that reading performance does not particularly rely on spoken ability.

Finding the key word (LPL1, LPL3, LPL4)

Finding the key word, a reading strategy frequently performed by PL learners, emerged in the three LPL learners These learners performed the strategy within the different set of task in the reading. LPL1 immediately demonstrated the strategy at the beginning of her reading. She said, 'the title is mosquito with a mission, and hmm before I err answer the question I want to know about what err... what err the important that in the text'. LPL3 employed this strategy towards the end of his reading when he said, 'treated bed net...I think this is the phrase again...treated bed net can kill malaria'. LPL4 demonstrated the strategy and showed his vocabulary impediment. He said, 'the word is 'gaining' and maybe I need a dictionary to find the meaning of gaining'. He confirmed reading the subsequent paragraph to obtain substantial information to ensure better comprehension. Overall, these learners did use the strategy in rather different way and make use of it according to the level of difficulty that they encountered.

Code - Switching (LPL1, LPL2)

Code switching as an alternative strategy for resolving reading difficulties also appeared in the LPL group. LPL1 employed the strategy when encountering difficult word related to second statement. She said, ' $h m m / / . . . /$... I did not get it...but I think it's err talks about cure. I think it that meaning in Bahasa Indonesia 'dapat disembuhkan'. Two distinctive factors that hinder her overall comprehension of the text include vocabulary insufficiency and lack of text analysis skills that led her to text miscomprehension. As a typical EFL learner, she attempted range of strategies, such as switching to L1 and using dictionary when encountering unfamiliar word and declaring a comprehension. However, these were not sufficient tool to help her get the right answer. Overall, this learner also employed strategies that were evident in the proficient group but she was not able to internalize these strategies to extract and construct meaning from the text. A more frequent use of code switching was performed by LPL2 who did use the strategy both at the earlier part of her reading and at the final part. This learner employed the strategy that mostly concerned with lexical category as indicated in her expressions. She said, ' 'hmm...malaria...oh it means 'menghasilakan' has an exotic sound'. Moreover, the absence of affective strategy as well as social strategy that constitute lowering anxiety and encouraging her or taking emotional temperature would be a clear predictor that she was not an effective reader. Consequently, despite the presence of important strategies in her such as using first language, using a dictionary with unfamiliar word, rereading and restating these were not effective enough to resolve the task.

Indirect Strategy

Using Dictionary ((LPL1, LPL2, LPL3, LPL4)

Using dictionary among the LPL learners for this investigation is a most popular strategy. This strategy received the most frequent use in comparison with other strategies, such as inferring meaning from context and finding the key words. The high frequency use of this strategy provides a clear description about the mode of reading difficulty these learners encountered, such as lexical unfamiliarity. LPL1, LPL2 and LPL3 shared similar difficulty that led them to employ this strategy in that they both did not know the meaning of 'cure' in the text. 'Err...I don't know about curable, so that I need a dictionary to know that' (LPL1), 'I don't know the meaning of it so I will find it in the dictionary' (LPL2). 'Oh...may be the meaning is err...malaria can cure by treated bed net. Could I get the dictionary sir?'(LPL3). LPL4 oriented this strategy on different key word when he said, 'the word is gaining, and maybe I need a dictionary to find the meaning of gaining'.

Monitoring Comprehension (LPL3)

Monitoring comprehension, an important aspect of metacognitive reading strategy, is only evident in LPL3. This learner employed this strategy throughout his reading, which he deliberately used every time he encountered difficulty. At the very beginning of his reading he stated, 'whether I don't know I can find it in paragraph one'. In the next stage of his reading, he stated, 'well, actually I don't know the meaning of eradication, but let's see the next sentence'. In the last part of his reading, he declared, 'hmm...err I think I found the sentence that related to the sentence before'. In other words, he seemed to perform an active process of selecting information needed for completion of the task but he still needed to perform extra skills to make effective use of such reading skills. This learner displayed a range of strategy use such as stating the main idea while reading, compensating while reading, and previewing before reading.

Previewing (LPL3)

Previewing was only evident in LPL3 who declared, 'oh I have to preview the paragraph one until paragraph two may $b e$ '. This learner performed almost all of the listed strategies within the less proficient group. This learner is aware of the important use of range of strategies in reading such as scanning, skimming, predicting, and monitoring comprehension. He was able to display these aspects of strategies in every step of his reading but he failed to distinguish when it was important to read every detail and when it is not. He was rather wasting time to read the passage with the intention of understanding every single detail before he tried to answer the question. It is interesting to notice that while LPL3 performed almost all the listed strategies, he only scored four out of six TF statements that were relatively lower in comparison with LPL2 who performed fewer 
strategies. This evidence confirms that the number of reading strategies performed does not account very much for the level of text comprehension in EFL learners.

\section{Conclusion}

Findings of this study have revealed that there are variations in the reading stratergy use by the less proficient learners. Evidence of the use of range of strategy in these learners leads us to infer that reading is fundamentally a cognitive process that requires conscious attention regardless of level of proficiency. The study confirms that range of strategy use is still insufficient for EFL learners to enhance comprehension due to their restricted vocabulary. The findings also confirm that the presence of main reading strategy use, such as cognitive and metacognitive strategy does not warrant strategic and efficient reading for EFL background. The findings bring significant challenges to the existing literature maintaining that students are required to actively employ a repertoire of reading strategies to construct meaning (Shuyun \& Munby (1996)).

Self-reliance in terms of resolution to reading problems was clearly evident in almost all of the learners. These learners tended to be more assertive and declarative in terms of expressing feeling when facing reading constraints. Support strategy was generally used to overcome the lexical problems that emerged in the reading. Finding key words as the basis to determine the reading purpose was practiced by only some of the learners. Overall, these proficient learners also performed almost all of the important reading strategies commonly practiced by learners of ESL background. These learners' lexical dependency is in line with a consensus among reading scholars who bring up lexical issues as essential for comprehension. The findings strengthen the validity of previous revelations confirming that there may not be specific strategy that is effective for all types of learners. However, these findings warrant the needs for explicit strategy instruction in order to make the learners' strategy use more effective and efficient.

\section{References}

[1] Abidin Pammu; Zaini Amir; Tengku Nor Rizan Tengku Mohd Maasum. (2013). Metacognitive Reading Strategies of Less Proficient Tertiary Learners: A Case Study of EFL Learners at a Public University in Makassar, Indonesia. Sollsintec Proceding 2013.

[2] Abidin Pammu, Zaini Amir, Tengku Nor Rizan Tengku Mohd Maasum. 2012. Metacognitive awareness in reading strategies: A case study of proficient learners at Hasanuddin University, Indonesia. ICOSH 2012 Proceeding. UKM. Bangi.

[3] Alvermann, D. E., \& Phelps. S. F. (2002). Content reading and literacy. Succeeding intoday's diverse classrooms. (3rd Ed.). London: Allyn and Bacon. Language Acquisition. USA. Cambridge University Press.

[4] Anderson, J. R. (1985). Cognitive psychology and its implications. 2nd ed. New York. Freeman.
[5] Bernhardt, E. B. (1991). Reading Development in Second Language. New Jersey. Alex Publishing Corporation.

[6] Brown, R., Pressley, M., VanMeter, P., \& Schuder, T. (1996). A quasi-experimental validation of transactional strategy instruction with low-achieving secondgrade readers. Journal of Educational Psychology, 88, 18-37.

[7] Cahyono, Bambang Yudi \& Widiati, Utami. (2006). The teaching of EFL reading in the Indonesian context: The state of the art. TEFLIN Journal, Volume 17, Number1, February 2006.

[8] Call, M. E. (1985). Auditory short term memory, listening comprehension and the input hypothesis. TESOL Quarterly 19:765-781.

[9] Carrell, P. L. (1998). Interactive Approaches to Second Language Reading. Cambridge. Cambridge University Press.

[10] Cohen, A. D. (1998). Strategies in Learning and Using a Second Language. New York. Longman.

[11] Ericson, K. A. \& Simon, H. A. (1984). Protocol Analysis. In Faerch, C. \& Kasper, G. (1987). Introspection in Second Language Research. England. Multilinguals Ltd.

[12] Erna Iftanti. 2012. A Survey of the English reading habits. TEFLIN Journal, Volume 23, Number 2, July 2012.

[13] Gardner, R. C. \& Mac Intyre, P. D. (1991). An instrumental motivation in language study: Who says it isn't effective? Studies in Second Language Acquisition, 13, 266-272.

[14] Graham, Suzanne. (2007). Learner strategies and selfefficacy:Making the connection. Language Learning Journal. Vol.35 No.1 June 2007. pp, 81-93

[15] Grenfell, Michael. 2007. Language learner strategies. Language Learning Journal. Vol.35 No.1 June 2007, pp.5-7

[16] Gunawan, M. Handi. 2008. Teachers' understanding of EFL principles \& their ability to apply the principles in teaching practice. Paper on "globalizing Asia": The role of ELT. The $6^{\text {th }}$ ASIA TEFL International Conference. Sanur. Bali (1-3) August 2008.

[17] Hajibah Osman. (2004). Genre based instructions for ESP. The English Teacher. XXXIII, 13-29.

[18] Hamra, A. (1996). Developing questioning competencies through radio reading. Journal Jaringan. 1 (3): 195-199.

[19] Jariah Mohd Jan \& Rosli Talif. (2005). Questioning strategies and the construction of context in classroom talk. The English Teacher, XXXIV, 76-89.

[20] Jitendra, Asha K., Burges, Clare, Gajria, Meenakshi. (2011). Cognitive strategy instruction for improving expository text comprehension of students with learning disabilities. Exceptional children. Winter 2011. Vol.77; 2 Pro Quest P.135.

[21] Juliana Othman; Abu Bakar Nordin.(2013). MUET as a predictor of academic achievement in ESL teacher education. GEMA Online Journal of Language Studies. Volume 13(1), February 2013.

[22] Just, M. A. \& Carpenter, P. A. (1987). Thepsychology of reading and language comprehension. In Bernhardt, E. B. 1991. Reading Development in Second Language: Theoretical, Empirical, \& Classroom Perspectives. New Jersery. Ablex Publising Corporation. 
[23] Kligner, J. K., Vaughn, S., Arguelles, M. E., Hughes, M. T., Leftwis, S. A. (2004). Collabvorative strategic reading: 'Real Word' lesson from classroom teacher, remedial and special education, 25. 291-302.

[24] Koo Yew Lie \& Peter Kell (2006). Language, literacy and education in diverse contexts:Theory, research and practice. 3L. Journal of Language Teaching, Linguistics \& Literature. Vol.112006.

[25] Kweldju, S. (2001). Vocabulary and lexicogramatical unit: Graduate students' main problems in reading their textbooks. Linguitic Indonesia journal ilmiah masyarakat linguistic Indonesia. 1: 35-56.

[26] Liando Nihta, V. F. (2000). Some perspectives in improving English as a foreign language program in Indonesian schools. Paper in TEFLIN Conference. The 48th International TEFLIN Conference. Jakarta.

[27] Lie, Anita. (2007). Education policy and EFL curriculum in Indonesia: Between the commitment to competence and the quest for higher test score. TEFLIN Journal: 8 (1) 1-1.

[28] Lynch, B., \& Hudson, T. (1991). EST reading. In M. CelceMurcia (Ed.), TeachingEnglish as a second or foreign language (2nd ed.) (pp. 216-232). Boston: Heinle \& Heinle. (1) $1-1$.

[29] Mc-Cardle, P. S., Scarabough, P. \& Catts, H. W. (2001) Predicting, explaining, and preventing children's reading difficulties. Learning disabilities research \& practice, 16, 230239 .

[30] Mercer, Sarah \& Ryan, Stephen. 2011. A Mindset for EFL:Learners' beliefs about the role of natural talent. ELT Journal. Vol.64/4 October 2010.

[31] Muhammad Kamarul Kabilan; Mak Kem Seng; Ooi Ae Kee. (2010). Reader-text transaction in text comprehension. GEMA Online Journal of Language Studies. Volume 10(3)2010.

[32] National Accessible Reading Assessment Projects. (2006). Defining reading proficiency for accessible assessments: Some guiding principles and issues. Minneapolis, MN: Author.

[33] Norizah Mohd. Noor. (2010). ESL learners' reading approaches of an academic expository text.3L The Southeast Asian Journal of English Language Studies Vol. 16 (2) 2010.

[34] O’Malley, J. M. \& Chamot, A. U. (1999). Learning Strategies in Second Language Acquisition. USA. Cambridge University Press.

[35] Oxford \& Nyikos, M. (2001). Variables affecting language learning strategies. Asian Journal of ELT. Vol. 11. 2001.

[36] Ozek, Y. \& Civelek, M. (2007). A study on the use of cognitive reading strategies by ELT students. The Asian EFL Journal. Professional Teachers Articles. August 2006.

[37] Pearson, P. D., \& Gallagher, M. C. (1992). The instruction of reading comprehension. Contemporary Educational Psychology, 8(3), 317-344.
[38] Richards, J. C. (2008). Second language teacher education today. SAGE publication. Vol. 39(2) 158-177. RELC Singapore.

[39] Rosenshine, B., \& Meister, C., \& Chapman, S. (1996). Teaching students to generate questions: A review of the intervention studies. Review of Educational Research, 66(2), 181.

[40] Shorey, R. \& Mokhtari, R. (2001). Differences in the metacognitive awareness of reading strategies among native and non-native readers. System. 29:431-449.

[41] Silberstein, S. (1987). Let's take another look at reading: Twenty-five years of reading instruction. Language Teaching Forum, 25(4): 18-35.

[42] Simpson, M. L. \& Rush, L. (2003). College students' beliefs, strategy employment, transfer, and academic performance: An examination across three academic disciplines. Journal of College Reading and Learning. 33 (2), 146-156.

[43] Soewartono. (2008). The strategies of the minority: Success story of secondary better performing learners of EFL. Paper presented in $6^{\text {th }}$ ASIA TEFL. 1-3 August 2008. Sanur. Bali. Indonesia.

[44] Syatriana, E. (1998). The levels of reading comprehension of the fifth semester students of STKIP YPUP Makassar. Unpublished Sarjana Thesis. Makassar.

[45] Shuyun, L. \& Munby, H. (1996). Metacognitive strategies in second language academic reading: a qualitative investigation. English for Specific Purposes, 15(3), 199-216.

[46] Walters, Sue. 2007. Researching Bangladeshi pupils' strategies for learning to read in (UK) primary school settings. Language Learning Journal. Vol.35 No.1 June 2007.

[47] Whitehead, J. (2007). The British Council and English Language in East Asia: Setting the Context. In Primary Innovations Regional Seminar. A collection of papers. Hanoi. The British Council.

[48] William \& Burden. (1997). Cited in Ozek, Y. \& Civelek, M. 2007. A study on the use of cognitive reading strategies by ELT students. The Asian EFL Journal. Professional Teachers Articles. August 2006.

\section{Biography}

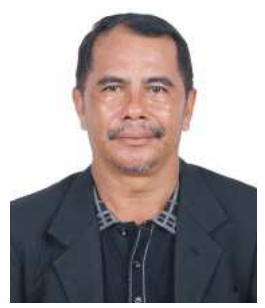

Abidin Pammu is a member of teaching staff at the English Department, Faculty of Cultural Sciences, Hasanuddin University, Makassar, South Sulawesi and has been teaching at the institution since 1985. He obtained Master degree in TESOL from Canberra University, Australia, in 1994 and $\mathrm{PhD}$ in the same field from the National University of Malaysia in 2015. Interest areas include EFL Reading Strategies, TEFL, ESP, and Language Testing and Evaluation. 